
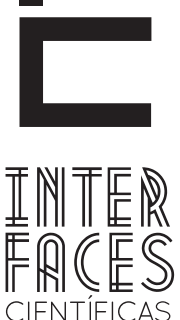

HUMANASE SOCIAIS

\title{
POLÍTICAS PÚBLLICAS E DIREITOS HUMANOS: IMPACTOS PROVOCADOS PELA OCUPAÇ̃̃O IRREGULAR NA ZONA DE EXPANSÃO DE ARACAJU, ESTADO DE SERGIPE
}

Vania Fonseca

Ana Célia Goes Melo Soares"
Miraci dos Santos Correia"II

\section{RESUMO}

0 artigo trata da ocupação da Zona de Expansão de Aracaju, área de equilíbrio frágil, e seus reflexos socioambientais decorrentes de problemas provocados pela ação inadequada dos gestores municipais, interesses políticos, ocupações irregulares. 0 estudo, realizado com base em análise bibliográfica e cartográfica, uso de dados secundários de cadastros e arquivos e levantamentos de campo, permite observar o conflito entre a concepção e execução de políticas públicas e a falta de cuidado em adequar as várias políticas entre si. 0 estudo conclui que mais do que novas polí- ticas públicas, é necessária a articulação entre as políticas já existentes, de forma a impedir que a execução de uma política prejudique as demais, fato que reflete mais significativamente nas classes mais baixas, justamente aquelas que boa parte das políticas visa beneficiar.

\section{PALAVRAS-CHAVE}

Zona de Expansão. Crescimento Urbano. Planejamento e Execução de Políticas Públicas. 


\section{ABSTRACT}

The article deals with the occupation of the Expansion Zone of Aracaju, fragile balance area, and its effects arising from environmental problems caused by inadequate action of municipal managers, political interests, irregular occupations. The study, based on bibliographic review and mapping, use of secondary data from files and records and field surveys, allows us to observe the conflict between the design and implementation of public policies and lack of care to suit the various policies together. The study concludes that more than new public policies is required coordination between existing policies in order to prevent the implementation of a policy harms the other, a fact that reflects more significantly in the lower classes, precisely those that most policies designed to benefit.

\section{KEYWORDS}

Expansion Zone. Urban Growth. Planning and Execution of Public Policies.

\section{INTRODUÇ̄̃OO}

As cidades brasileiras, especialmente as de porte médio e grande, nos últimos 50 anos vêm passando por um crescimento acelerado, não devido ao crescimento vegetativo da população urbana, mas à imigração de pessoas antes residentes em cidades de menor porte ou provenientes da zona rural. A migração se faz em busca de um local que proporcione melhores condições de trabalho e, segundo dados do Instituto Brasileiro de Geografia e Estatística (IBGE), o Brasil já ultrapassou a marca de $80 \%$ da população residente em zonas urbanas (IBGE, 2012).

\section{RESUMEN}

El artículo trata de la ocupación de la Zona de Expansión de Aracaju, área de equilibrio débil, y sus reflejos socio-ambientales debido a problemas provocados por la acción inadecuada de los gestores municipales, intereses políticos, ocupaciones irregulares. El estudio, realizado con base en análisis bibliográfica y cartográfica, uso de datos secundarios de registros y archivos y levantamientos de campo, permite observar el conflicto entre la concepción y ejecución de políticas públicas y la falta de cuidado en adecuar las varias políticas entre sí. El estudio concluye que más que nuevas políticas públicas, es necesaria la articulación entre las políticas ya existentes, de forma a impedir que la ejecución de una política perjudique las demás, hecho que refleja más significativamente en las clases más bajas, justamente aquellas que buena parte de las políticas visa beneficiar.

\section{PALABRAS CLAVE}

Zona de Expansión. Crecimiento Urbano. Planeamiento y Ejecución de Políticas Públicas.

0 crescimento acelerado, muitas vezes com população pobre ou muito pobre, tem feito com que a expansão urbana não se dê de forma organizada e muitos bairros surgem com ocupação desordenada do espaço, por vezes em áreas impróprias à edificação, o que dificulta ao poder público a necessária dotação de infraestrutura básica. A gestão urbana, além de esbarrar em muitas dificuldades de atendimento a esse crescimento sem qualquer planejamento, também encontra outro fator limitante, que é o comprometimento de verbas para a dotação de infraestrutura de água e esgoto, arruamento, energia elétrica, telefo- 
nia, transporte público, escolas, postos de saúde e outros, sem expectativa de retorno, pois a população de baixa renda deve ter esse conjunto de infraestrutura subsidiada (ROLNIK, 2002; KRELL, 2002).

$\mathrm{Na}$ atualidade moradia é conceituada não simplesmente como uma edificação, mas um "habitat", onde seja assegurado um local salubre, com adequadas condições de habitabilidade, com segurança, abastecimento de água, esgotamento sanitário, coleta de lixo, acesso a emprego e aos equipamentos sociais e serviços urbanos, entre outros (BRASIL, 2008; BRASIL, 2006).

0 direito à moradia é um direito humano, assim como o direito à Cidade, legitimado internacionalmente por intermédio da Declaração dos Direitos Humanos ONU, 1948 e da Conferência Internacional do Habitat II, realizada em Istambul no ano de 1996. No âmbito nacional, sua legitimidade é verificada pela Constituição Federal, no Estatuto da Cidade - Lei Federal n. ${ }^{\circ}$ 10.257/01, na medida provisória 2.220, na Carta Nacional do Direito às Cidades - 2001.

Assim, não se deve reduzir o habitat somente ao domicílio, ao alojamento. Ele é um espaço frequentado por indivíduos e grupos, lugar de trabalho, de circulação, de divertimento e de repouso. É nesse espaço que valores, identidades e ética dos grupos se projetam, onde se realizam suas representações coletivas, seus sonhos, seus desejos e reflexões (ALFONSIN; FERNANDES, 2003).

A moradia geralmente é um bem de grande valor para o desenvolvimento da família e dos grupos sociais, pois fixa o homem ao lugar e permite a sua interação social com outros moradores. Além disso, se diferencia das demais necessidades básicas, pois tem como pressuposto o acesso a terra, e pode facilitar ou dificultar o acesso a serviços de saúde, educação e segurança, além de atividades de geração de renda, de lazer e muitas outras que dependem da interação social e permitem aos indivíduos e aos grupos terem condições de desenvolver suas capacidades. Diante destes elementos a moradia é um direito básico de cidadania e de qualidade de vida. Para Andreas Krell (2002, p.19),
[...] os direitos Fundamentais Sociais não são direitos contra o Estado, mas sim direitos através do Estado, exigindo do poder público certas prestações materiais. São os direitos Fundamentais do homem social dentro de um modelo de Estado que tende cada vez mais a ser social, dando prevalência aos interesses coletivos antes aos individuais.

São muitos e poderosos os interesses políticos envolvidos na produção da moradia e do espaço urbano, podendo haver grande tolerância dos gestores urbanos, permitindo a ocupação de áreas inadequadas à construção, mas que estão mais prontamente acessíveis e favorecem os interesses de grupos que apoiam o poder.

A busca incessante por espaços para habitação e trabalho contribuiu para que aumentassem, de forma acentuada, os conflitos sociais nas cidades, locais onde a tradição de competição entre classes sociais está bastante presente, reforçando a ocupação desordenada de áreas pouco adequadas à construção de moradias e onde o formal e informal disputam espaço no meio físico (CAMPOS, 2005).

Os gestores urbanos, procurando oferecer equipamento residencial para a população mais pobre, só tem condições de construir casas de baixo custo e em locais onde o solo é menos valorizado. E são essas áreas de menor valor que mais carecem de infraestrutura urbana, e a população ali assentada passa a reivindicar os serviços básicos fundamentais, muitas vezes demorando anos para que essas reivindicações sejam atendidas. E quando a infraestrutura urbana é implantada e passa a funcionar, toda a área é valorizada e ali passa a atuar a especulação imobiliária, muitas vezes forçando a saída da população residente mais antiga, devido ao aumento dos impostos nessa área valorizada e a necessidade de pagar pelas melhorias instaladas (FRANÇA, 2004; NOGUEIRA, 2004).

A Zona de Expansão de Aracaju é um caso bastante típico dessa situação pois, ao ser declarada legalmente área urbana, praticamente refletiu na expulsão dos antigos habitantes que exploravam pequenos sítios 
e roças e não puderam arcar com o ônus do Imposto Territorial Urbano e das benfeitorias na infraestrutura. Além desse primeiro grande impacto socioeconômico, a área passou a ser utilizada para a construção de casas populares, especialmente do Programa de Arrendamento Territorial (PAR), sobre terrenos de baixa altitude, quase ao nível do mar, com lençol freático muito próximo ao nível do solo, dificultando e encarecendo a implantação de infra-estrutura urbana, especialmente esgotamento sanitário e escoamento de águas pluviais (FONSECA; GONZAGA JÚNIOR, 2010).

0 rápido crescimento do uso e ocupação do solo fez aumentar bastante o trânsito de carros e pedestres sem que as vias de transporte fossem adequadas a esse novo volume de usuários, fato piorado devido à construção de uma ponte sobre o Rio Vaza Barris, ligando a porção sul de Aracaju - onde se situa a Zona de Expansão - à Rodovia SE100, conhecida como Linha Verde que liga Sergipe à Bahia com pavimentação de boa qualidade (FONSECA; GONZAGA JÚNIOR, 2010).

Visando conhecer melhor a realidade da Zona de Expansão e os reflexos socioambientais da sua ocupação, foi realizado este estudo, com análise da bibliografia e da cartografia sobre a região, levantamento de campo com observação direta, dados secundários de cadastros oficiais e de pesquisa disponibilizada pelo Instituto de Tecnologia e Pesquisa e pelo Núcleo de Pesquisa Sobre Violência e Desastres.

\section{A ZONA DE EXPANSÃO DE ARACAJU}

A Zona de Expansão de Aracaju, localizada na porção sul do município, corresponde a quase $40 \%$ do território municipal e se caracteriza por altitudes muito baixas, próximas ao nível do mar, apresenta solos muito heterogêneos e concentra a maior parte do vazio urbano. A área tem ocupação antiga, embora o processo da divisão das terras e adensamento do uso do solo com edificações tenha sido iniciado na década de oitenta do século passado (FONSECA e GONZAGA JUNIOR, 2010).

A ocupação urbana da área onde hoje é a Zona de Expansão de Aracaju, se deu a partir do início do século $X X$, em base territorial que, até então, abrigava apenas povoados pertencentes ao vizinho município de São Cristóvão (WANDERLEY; GONÇALVES, 2005). Essa ocupação se acelerou no Século $X X I$, fruto do crescimento urbano de Aracaju e do forte interesse do setor imobiliário na implantação de condomínios residenciais para classe média alta. 0 crescimento também se dá devido à necessidade de construção de casas populares, especial-

mente do Programa de Arrendamento Residencial, estimulando o acelerado crescimento da população residente nessa área que, no período de 2007 a 2010, passou de 18.933 para 36.310 habitantes, perfazendo o notável crescimento de $21,53 \%$ em apenas três anos (IBGE, 2012).

Visando a implantação de política habitacional para as classes baixa e média, muitas áreas inadequadas foram ocupadas com construções e áreas embrejadas foram aterradas para criação de solo urbano sem o devido cuidado com o sistema de drenagem, o que resultou em muitos problemas decorrentes da infraestrutura implantada em área de lençol freático muito raso, fato responsável pela ocorrência de enchentes, especialmente por ocasião do período chuvoso, que trazem grandes transtornos aos moradores desse bairro.

$\mathrm{Na}$ área pode ser observado que o uso do solo tipicamente urbano se intercala ao uso do solo de características rurais, com 
[...] casas de veraneio à beira rio, ao lado de condomínios habitacionais de classe média alta e média, conjuntos habitacionais de baixa renda - especialmente do Programa de Arrendamento Residencial e outros, estimulados pelo Programa Minha Casa Minha vida e sítios bastante pobres, além de casa de pescadores, especialmente marisqueiras, embora essa atividade esteja quase extinta na área”. (FONSECA; GONZAGA JÚNIOR, 2010, p.69)

Observações de campo permitiram verificar que a zona de expansão urbana de Aracaju funciona como um bairro dormitório, que não estava preparado para receber o grande contingente de habitações e seus moradores, quer devido ao meio natural frágil e alterado sem o necessário cuidado, quer devido à falta de infraestrutura de saúde, de ensino e de transportes, de setor comercial e de serviços para atendimento local. Isso faz com que a população residente tenha que buscar em outras partes da cidade esse tipo de atendimento, o que impacta ainda mais o sistema de transportes, bastante acanhado nessa área e com ligação às outras partes da cidade se fazendo apenas por três pontes, fator agravado pela insuficiência e inadequação sistema de transportes coletivos de Aracaju.

Os problemas vinculados ao meio natural, à inadequação da infraestrutura e à ocupação urbana da área, refletem em outra sequência de problemas que podem ser registrados pela simples observação direta: falta de escoamento das águas pluviais causando inundações, aumento de processos erosivos, formação de lagoas e charcos que servem de reservatórios de mosquitos e de outros vetores como o Aedes Aegypti, transmissor da dengue, o caramujo hospedeiro do molusco responsável pela esquistossomose, os ratos que transmitem a leptospirose e o flebotomíneo, que transmite a leishmaniose visceral, também conhecida por calazar.

A análise comparativa das condições de saúde dos bairros do município de Aracaju que apresentaram rápido crescimento populacional nos últimos três anos, destaca a Zona de Expansão por apresentar altos índices das doenças de veiculação hídrica de maior ocorrência no Estado de Sergipe: lesishmaniose visceral
(96,6/100 mil hab.), esquistossomose (393,6/100 mil hab.), letpospirose (21,5/100 mil hab.) e dengue (2383,3/100 mil hab.). Esse fato é ainda agravado pelos cenários tendenciais de crescimento populacional e permanência dos problemas de infraestrutura e de condições socioambientais adversas na Zona de Expansão, que são favoráveis à manutenção de índices crescentes dessas doenças de notificação compulsória se providências adequadas não forem tomadas par a reversão dessa tendência.

$\mathrm{Na}$ área pode ser observada a prática comum de uso de poços artesianos, especialmente na praia do Robalo, no povoado de Areia Branca e no povoado do Mosqueiro, fato decorrente de dois fatores conjugados: facilidade de perfurar poços devido ao lençol freático alto e problemas no abastecimento domiciliar com água tratada. 0 uso de poços artesianos perfurados próximos a fossas de esgoto residencial, que drenam para a areia e contaminam os poços, se constitui em outro fator de risco para a saúde dos moradores, o que ainda é agravado pela existência de vários cemitérios clandestinos na área.

A esses problemas somam-se problemas de sobrecarga da malha viária, bastante acanhada na zona de expansão urbana de Aracaju, que é cortada por apenas duas avenidas que dão acesso a pequenas ruas de entrada para conjuntos e condomínios, e caminhos de traçado irregular ligando habitações construídas sem qualquer tipo de ordenamento, mantendo o traçado de antigos povoados, reforçado por novas habitações sem o necessário planejamento do uso do solo. Várias dessas vias de trânsito, geralmente de má qualidade, foram assentadas em aterros de áreas embrejadas, o que contribui para agravar os problemas de escoamento de águas pluviais da área e dificultar e, por vezes, impossibilitar, o tráfego de veículos, isolando os moradores que têm comprometido o seu direito de ir e vir.

Recentemente vem sendo observado um outro tipo de problema: deterioração da infraestrutura 
viária e infraestrutura residencial, decorrente da inadequação de projetos/execução, fato agravado pelas condições do terreno em que foram assentadas. É possível observar unidades residenciais populares com paredes rachadas e muitos problemas de vazamento do sistema de esgoto, rodovias em mau estado e com alguns trechos parcialmente destruídos.

\section{CONSIDERAÇÕES FINAIS}

O crescimento da capital sergipana com a ocupação da área da Zona de Expansão, transformada em bairro, ao mesmo tempo em que atendeu os objetivos das políticas públicas vinculadas à habitação, trouxe uma série de problemas porque outras políticas públicas não foram contempladas, como é o caso da dotação de infraestrutura física, especialmente saneamento, escoamento de águas pluviais e vias de tráfego. Também não foram contempladas políticas de educação e saúde, pois o atendimento à população residente é precário, sendo que os moradores se vêm obrigados a procurar em outros bairros esses serviços públicos.

A ação do Estado para o desenvolvimento na localidade, se deu de forma pouco adequada, pois foram ocupadas áreas impróprias à construção, houve permissão para a construção de condomínios fechados de luxo que interromperam a drenagem natural da área causando problemas para a população de menor poder econômico. Também foram implantados conjuntos residenciais para população de baixa renda em áreas que deveriam ser protegidas, como dunas, restingas, mangues e áreas embrejadas, sem que houvesse o necessário cuidado com o tipo de construção assentada sobre elas, fazendo com que o custo de manutenção seja muito alto e proibitivo para essa população atendida por políticas de habitação para classe baixa.

O caso da Zona de Expansão de Aracaju permite observar o conflito entre a concepção e a execução das políticas públicas, pois não há cuidado em adequar as várias políticas umas às outras, nem há cuidado na execução de cada uma delas. Assim, mais do que novas políticas públicas, o que é necessário é a articulação entre as políticas já existentes, de forma a impedir que a execução de uma política prejudique outras e, como reflexo, aumente os problemas para as classes mais baixas, justamente aquelas que boa parte das políticas visa beneficiar.

\section{REFERÊNCIAS}

ALFONSIN, Betânia e FERNANDES, Edésio. A lei e a Ilegalidade na Produção do Espaço Urbano. Belo HoBRASIL. Caderno CIDADES HABITAÇÃO: Política Nacional de habitação. 4 mai. 2006. 
BRASIL. Direito Humano a Moradia e Terra Urbana. Plataforma DHESCA, Brasil, 2008. Disponível em: <www.dhescabrasil.org.br>. Acesso em: 18 mai. 2012.

CAMPOS, Antônio Carlos. O Estado e o Urbano: os Programas de Construção de Conjuntos Habitacionais em Aracaju. Revista do Instituto Histórico e Geográfico de Sergipe. Aracaju, v.1, p.199-222, 2005.

FONSECA, Vania. GONZAGA JÚNIOR, Antonio Fernando Cabral. Mapeamento sócio-ambiental dos bairros de Aracaju. Relatório de pesquisa. Aracaju: ITP/ UNIT/CNPq, 2010.

FRANÇA, Sarah Lúcia Alves França. Os condomínios fechados na Zona de Expansão Urbana de Aracaju: uma nova modalidade de segregação sócio-espacial. Trabalho de Conclusão de Curso (Graduação em Arquitetura e Urbanismo) - Universidade Tiradentes, 2004.

IBGE. Censo Demográfico do Brasil - 2010. Instituto Brasileiro de Geografia e Estatística, 2012.

Recebido em: 25 de julho de 2012 Avaliado em: 27 de julho de 2012 Aceito em: 17 de outubro de 2012
KRELL, A. J. Direitos Sociais e controle judicial no Brasil e na Alemanha. Os (des) caminhos de um direito "constitucional" comparado. Porto Alegre: Sergio Antonio Fabris Editor, 2002.

NOGUEIRA, Adriana Dantas. Análise sintático-espacial das transformações urbanas de Aracaju (1855 a 2003). Tese (Doutorado em Arquitetura e Urbanismo) - Universidade Federal da Bahia, 2004.

ROLNIK, R. É possível uma política urbana contra a exclusão? Revista Serviço Social e Sociedade, São Paulo, Ano 23, nº 72, p. 53-61, nov. 2002.

WANDERLEY, Lilían; GONÇALVES, Hortência de Abreu. Paisagens da Zona de Expansão de Aracaju: natureza e atores sociais na produção do espaço geográfico. Caderno de Pesquisa e Extensão Desafios Críticos - CEPEDeC. Aracaju, v.1, n.1 ago/dez. 2005.
I Professor-orientador do Curso de Mestrado em Saúde e Ambiente - Unit. Pesquisador do Laboratório de Planejamento e Promoção da Saúde - ITP -vania@infonet.com.br

II Professora dos cursos de Serviço Social e de Medicina. Mestranda do Curso de Saúde e Ambiente da UNIT - anaceliagoes@hotmail.com

III Pesquisadora em projeto Fapitec-SE - correiasocial@bol.com.br 